\title{
O ENSINO DE CALIGRAFIA, DESENHO DE LETRAS E TIPOGRAFIA NO LICEU DE ARTES E OFÍCIOS DE SÃO PAULO
}

José Roberto D'Elboux

Faculdade de Arquitetura e Urbanismo da Universidade de São Paulo

delboux@usp.br

Resumo: O presente artigo aborda aspectos do ensino de caligrafia, desenho de letras e tipografia, dentro dos cursos profissionalizantes para desenhistas e artífices oferecidos pelo Liceu de Artes e Ofícios de São Paulo, a partir de sua fundação, no ano de 1873, até meados da década de 1940. A partir do resultado obtido em pesquisa documental feita no acervo histórico dessa instituição, fez-se uma análise dos conteúdos e dos aspectos práticos desse aprendizado, relacionando-os à utilização das letras no âmbito do desenho arquitetônico e na elaboração e produção de elementos decorativos para a construção civil e de letreiros comerciais.

Palavras-chave: Tipografia, Letreiramento, Caligrafia, Desenho Arquitetônico, Liceu de Artes e Ofícios.

\begin{abstract}
This paper focuses on the teaching aspects of calligraphy, lettering and typography in the courses for draftsmen and craftsmen at Liceu de Artes e Ofícios de São Paulo, from its opening in 1873 until the mid 1940. The analysis of the courses was made through a documental research in the archives of the institution, and relates the practical aspects of the use of lettering in architectural drafting, design and production of decorative elements for buildings and commercial signs.
\end{abstract}

Keywords: Typography, Lettering, Calligraphy, Archictectural Drawing, Liceu de Artes e Ofícios. 


\section{INTRODUÇÃO}

O objetivo deste trabalho, foi verificar e analisar a existência de conteúdo relativo ao ensino do desenho de letras, caligrafia e tipografia, no currículo dos cursos ministrados pelo Liceu de Artes e Ofícios de São Paulo a partir de sua fundação em 1873, como Sociedade Propagadora da Instrução Popular, até o final da década de 1940.

Esta investigação insere-se em contexto mais amplo, em uma tese de doutorado em andamento no Programa de Pós Graduação da FAUUSP, na qual o objeto de estudo é o desenho das letras utilizadas como suporte de informações em projetos arquitetônicos, especialmente aquelas alinhadas formalmente ao estilo Art Déco. Nesse sentido, tornou-se essencial a investigação e a análise desse assunto, no conteudo do principal curso de formação técnica de mão de obra para escritórios de arquitetura e engenharia nesse período. A pesquisa foi conduzida a partir da revisão da bibliografia existente sobre o curso, assim como através de uma pesquisa documental realizada no acervo histórico da instituição.

\section{BREVE HISTÓRICO DO LICEU DE ARTES E OFÍCIOS DE SÃO PAULO}

O Liceu de Artes e Ofícios de São Paulo, teve sua origem com a instalação da Sociedade Propagadora da Instrução Popular em 1873, fundada pela necessidade de qualificação de uma classe trabalhadora, cada vez mais solicitada pelos novos processos industriais em implementação na cidade.

Em 10 de setembro de 1882, a escola noturna da então chamada Propagadora, foi reorganizada e ampliada, passando a ser denominada Liceu de Artes e Ofícios de São Paulo, tendo como objetivo "ministrar gratuitamente ao povo os conhecimentos necessários às artes e ofícios, ao comércio, à lavoura e às indústrias"1. Para isso, promoveu a ampliação de seu curso primário, de sua biblioteca e criou um Curso Especial de Artes e Ofícios e um de Comércio e Agricultura.

O programa dos novos cursos do Liceu foram divididos em dois grandes grupos: "Ciências Aplicadas", composto pelas disciplinas de Aritmética; Álgebra; Geometria Plana e Descritiva; Geologia; Zoologia; Botânica; Física; Química; Mecânica; Agrimensura; e Estereotomia; e "Artes", composto por Desenho Linear, de Ornato, de Figura e de Máquinas; de Arquitetura; Modelação; Escultura e Estatuária; Caligrafia; Gravura; Pintura; Fotografia; e Música (SEVERO, 1934, p. 14).

O funcionamento do Liceu de Artes e Ofícios estava ainda longe do ideal, e com a Proclamação da República, perturbações no cenário político trouxeram como consequência para o Liceu, a interrupção do apoio financeiro oficial.

Em 1895, um ano após voltar a receber subsídios oficiais, foi eleita uma nova diretoria presidida por José A. de Cerqueira César, tendo Francisco de Paula Ramos de

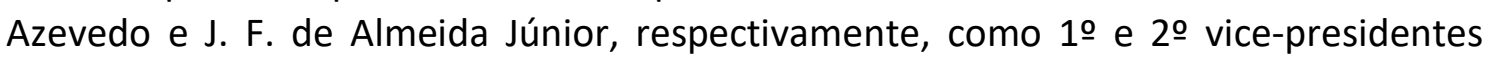
(SEVERO, 1934, p. 24).

Como principal arquiteto da cidade nesse período, Ramos de Azevedo além de responsável pelas grandes obras oficiais, como a reforma do largo do Palácio, mantinha participação societária em diversos negócios ligados ao ramo da construção civil, como financiamento, construção, fabricação e importação de materiais. Ao

\footnotetext{
${ }^{1}$ Conselheiro Francisco de C. Brandão, em fala dirigida à Assembléia Legislativa Provincial, em 10 de janeiro de 1883 (SEVERO, 1934, p.13; p. 169).
} 
assumir a vice-presidência e a direção geral do Liceu de Artes e Ofícios, Ramos de Azevedo percebeu a oportunidade de transformar a escola, num grande centro de aprendizagem de operários dedicados às áreas subsidiárias da arquitetura, como instalações, produção de objetos manufaturados para a construção civil e decoração de ambientes (BELLUZZO, 1988, p. 121; GORDINHO, 2000, p. 27).

Ramos de Azevedo promoveu uma série de mudanças no ensino do Liceu, introduzindo novas disciplinas no Curso Secundário e principalmente no Curso de Artes e Ofícios (SEVERO, 1934, p. 32), removendo algumas matérias teóricas e dando ênfase às disciplinas voltadas à construção, como o desenvolvimento do desenho linear, de ornato, de arquitetura e de máquinas (GORDINHO, 2000, p. 28).

Coube ao arquiteto italiano Domiziano Rossi, parceiro importante de Ramos que chegou a ser seu sócio no escritório, a responsabilidade de montar, supervisionar e também lecionar as disciplinas de desenho. Para Rossi, em um curso de formação profissional como o do Liceu "o aprendizado do desenho equivale ao conhecimento das primeiras letras" (Rossi apud BERTARELLI, 1924, p. 160).

O desenho passou a ser tão importante nessa etapa dentro do Liceu, que na orientação metodológica de seu novo regulamento, definiu-se como ponto central o então denominado Método Geometral, disciplina mental e social na qual a geometria é a base de todo o sistema pedagógico (SEVERO, 1934, p. 81).

Em 1895, o Liceu recebeu verbas do governo estadual para a construção de uma sede própria, que resultou no edifício construído entre 1897 e 1900 com autoria atribuída a Domiziano Rossi, e construção a cargo do Escritório Técnico F. P. Ramos de Azevedo. Este prédio é onde está abrigada atualmente a Pinacoteca do Estado na avenida Tiradentes (GORDINHO, 2000, p. 28).

Para serem admitidos no Liceu, os alunos deveriam ter idade mínima de 12 anos para ingressar no Curso Preliminar e 14 anos para o Curso Geral de Artes. Os melhores alunos geralmente eram convidados a permanecer nas oficinas, e muitos, tornaram-se professores do próprio Liceu, todos formados com visão global do processo de fabricação, evitando assim, especializações em determinadas etapas do trabalho (SEVERO, 1934, p. 82; GORDINHO, 2000, pp. 42-47).

Após a morte de Ramos de Azevedo em 1928, o arquiteto português Ricardo Severo, que havia se tornado seu grande colaborador e sócio no Escritório, transformou-se na principal figura dentro do Liceu. Ocupando o cargo de vicepresidente e diretor geral, Severo deu continuidade aos planos traçados por Ramos para a escola e cursos profissionalizantes até sua morte em 1940.

Dessa maneira, o projeto idealizado por Ramos de Azevedo se consolidou através da excepcional qualidade técnica e artística obtida pelos trabalhos do Liceu, parte integrante das construções e instalações das maiores e mais importantes obras arquitetônicas não só de São Paulo, mas de várias outras cidades brasileiras.

\section{O ENSINO DE CALIGRAFIA, DESENHO DE LETRAS E TIPOGRAFIA}

A Sociedade Propagadora da Instrução Popular, que mais tarde daria origem ao Liceu, transmitia em suas aulas noturnas conteúdo básico abrangendo a alfabetização, o ensino de gramática, aritmética e também caligrafia.

Segundo autores dedicados ao estudo da história dos processos de educação como Anne-Marie Chartier e Jean Hébrard, a escrita começou a ser ensinada simultaneamente à leitura, somente no início do século XIX. Esse fato foi possibilitado 
quando ainda no século XVIII, com o objetivo de ampliar o processo educacional, a burguesia começou a fazer pressão pelo fim da exclusividade do ato de escrever, ofício até então restrito aos monopólios corporativos. Posteriormente, outros fatores também colaboraram, como a invenção da pena metálica e do lápis, auxiliados pelo barateamento dos custos do papel e pela difusão do uso de pequenos quadros de ardósia pelos alunos (VIDAL; GVIRTZ, 1998, p. 13).

Em relatório de 1852 sobre o Estado de Instrução Provincial em São Paulo, já aparecem relacionados alguns manuais de caligrafia recomendados para utilização no ensino elementar, como os de autoria de Joaquim José Ventura da Silva; Carstairs e Butherworth; Antônio Jacinto de Araújo; Fortunato Rafael Hermano Wanzeller; José Inácio da Costa Miranda e a coleção de translados de Cirilo Dilermando da Silveira. (VIDAL; GVIRTZ, 1998, p. 16).

Em relatório de 1873 elaborado pelo Inspetor Geral de Instrução da Província de São Paulo, Francisco Aurélio de Sousa Carvalho, era indicado como modelo de letra a ser ensinada, a caligrafia americana, inclinada. Este padrão continuava vigente em 1904, segundo o Decreto 1217, de 19 de abril:

\begin{abstract}
Os exercícios de caligrafia acompanham as lições de leitura; assim, os alunos começarão, desde o primeiro dia de aula, a copiar letras, palavras e pequenas sentenças. Ao professor incumbe observar e corrigir a posição dos dedos e do corpo. No primeiro ano os exercícios serão feitos, no primeiro semestre, nas ardósias e, no segundo, no papel com lápis. Do segundo ano em diante serão usados os cadernos, cujo tipo principal de letra seja a norte americana, completando-se este ano com o ensino de letras de fantasia (VIDAL; GVIRTZ, 1998, p. 19).
\end{abstract}

Supõe-se então, que o ensino de caligrafia na Sociedade Propagadora iniciado em 1873, deveria seguir esse mesmo padrão em sua escola de primeiras letras.

A partir de 1882, com a reorganização que deu origem ao Liceu de Artes e Ofícios, o ensino de caligrafia passou a fazer parte do grupo das disciplinas de Artes, ao lado do Desenho Linear, de Ornato, de Figura, de Máquinas, e de Arquitetura. O professor era o catalão Narciso Figueras (SEVERO, 1934, pp. 14, 168).

Nascido em Girona, na Espanha, em 1854, Figueras exerceu as funções de litógrafo, gravador, caricaturista e calígrafo na cidade de Barcelona, tendo chegado ao Rio de Janeiro em 1879 (FREITAS, 2013). Naturalizado brasileiro em 1883, era bacharel em Letras e professor de caligrafia na Escola Normal do Rio de Janeiro (BLAKE, 1883, p. 304). Foi autor de três livros: Tratado Teórico-Prático de Caligrafia Moderna; Resumo Pedagógico Elementar do Tratado Teórico-Prático de Caligrafia Moderna, ambos de 1898; e Desenho Linear de Figura e Caligrafia, publicado em cadernos, que atingiu a marca de 611.000 exemplares em nove edições (BLAKE, 1883, p.304).

Sobre o Tratado Teórico-Prático de Caligrafia Moderna, o Jornal do Brasil em resenha publicada em 7 de março de 1898, ressaltou que teria sido esta, a obra mais completa já publicada sobre o gênero, apresentando uma metodologia clara, dirigida tanto àqueles que estão aprendendo, quanto aos que se dedicam ao ensino da caligrafia. A análise do jornal feita a partir do primeiro fascículo com 32 páginas, cita seis "modelos ou desenhos" caligráficos executados à pena pelo autor, diretamente sobre papel próprio para impressão em autografia ${ }^{2}$, técnica extremamente limitada,

\footnotetext{
2 Processo econômico de reprodução litográfica não mais em uso. O papel autográfico, usado para o transporte da imagem para a pedra litográfica, era feito a partir da aplicação de uma solução de amido, cola de peixe e outras gomas, diluídas em áua sobre papel fino (FONSECA, 2008, p. 164).
} 
mas que teria atingido resultado comparável às "finíssimas gravuras sobre pedras", atestando a habilidade de Figueras como artista gráfico.

O ensino de caligrafia foi constante no Liceu de Artes e Ofícios durante o período estudado, pois conforme registrado no programa da escola de 1934, aparece sob o tópico "Linguagem Escrita" no Curso Preliminar, consistindo da cópia de palavras escritas no quadro e em livro (SEVERO, 1934, p. 107).

No acervo do Liceu, encontra-se um antigo livro de visitas utilizado a partir do ano de 1930. Nele, eram registrados os visitantes que compareciam às exposições de trabalhos dos alunos, sendo possível observar alguns exemplos de escrita caligráfica realizadas dentro da escola (fig. 1).

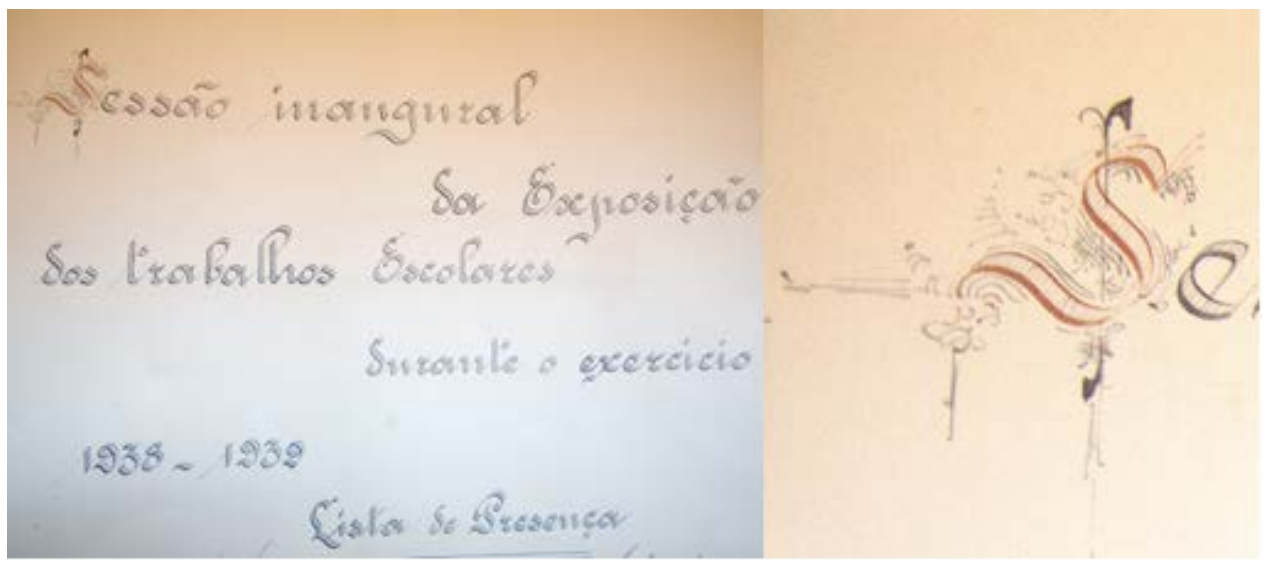

Figura 1 - Exemplo de trabalho de caligrafia com detalhe de capitular em livro de visitas do Liceu, com data de 1938-1939 (Acervo do Liceu de Artes e Ofícios).

\subsection{0 ensino do desenho de letras e tipografia após a reforma de $\mathbf{1 8 9 5}$}

A partir de 1895, sob a direção de Ramos de Azevedo, o Liceu obteve condições para atingir padrão de excelência como instituição formadora de mão de obra especializada, e tornou-se então, importante fornecedor de elementos complementares para a construção civil através da produção desenvolvida em suas oficinas.

Com a morte de Ramos de Azevedo em 1928, coube a Ricardo Severo a continuidade desse projeto, através de ações complementares como a ampliação dos cursos, a melhora nos equipamentos das oficinas e a realização de uma reorganização técnica. No novo estatuto publicado em 1934, foram detalhados os programas de cada curso e o conteúdo de suas aulas (SEVERO, 1934, pp.53-54). Esse registro, possibilitounos uma avaliação do conteúdo dos cursos, principalmente em relação ao ensino do desenho de letras.

O Curso Geral de Artes era composto de sete disciplinas: "Desenho Linear Geométrico", com conteúdo que incluia geometria plana; geometria no espaço; e geometria descritiva. "Desenho Linear a Mão Livre", que incluia desenho de estampa; desenho de ornato; e desenho de figura. "Desenho Arquitetônico", que incluia arquitetura; ordens arquitetônicas; e edificações. "Desenho Profissional", de conteúdo voltado à profissão para a qual se destinava o aluno. "Modelação", que consistia de materiais plásticos; técnica e utensílios para a modelação; modelação de ornatos à vista; modelagem; aplicação da modelação e moldagem às artes plásticas da cerâmica e terracota. "Desenho e Pintura nas Artes Decorativas", que incluia desenho 
decorativo; teoria das cores; pintura decorativa - tecnologia (materiais, utensílios, técnicas especiais); e pintura nas artes decorativas. "História da Arte - Estética", que consistia em Obra de Arte; História Geral das Belas Artes; História da Arte Americana; Arte Colonial; e Arte Moderna no Brasil.

Dentro do conteúdo programático de desenho de estampa, na disciplina de "Desenho Linear a Mão Livre", encontra-se o tópico 'Desenho dos Alfabetos' cujo conteúdo consistia no ensino de diferentes modelos de letras e também de processos para sua reprodução, como decalque, quadrícula, pontuação, reflexão, carbonos e processos químicos. Consta também desse conteúdo o ensino de aplicações em filigranas (marcas d'água) e guarnições de iluminura (capitulares ornamentadas) (SEVERO, 1934, pp.113-121).

Com esse registro, é possível notar que além do desenho de diversos estilos de alfabetos, também eram ensinadas técnicas de transferência, ampliação e aplicações das letras para diversas outras finalidades. Esse era um procedimento importante, pois garantia a fidelidade entre o que havia sido projetado e a execução final.

Convém lembrar como os desenhos decididos no escritório eram trabalhados no Liceu. O mestre geral de execução das obras... distribuía as tarefas para as seções com cotas e medidas já estabelecidas. Em cada seção havia um desenhista detalhista capaz de transpor a informação para os mestres modeladores em barro, em gesso, em cobre, que eram submestres com grande domínio de práticas específicas (BELLUZZO, 1988, p. 303).

A análise dos livros e guias práticos sobre letras disponíveis na biblioteca do Liceu de Artes e Ofícios, também possibilitou o conhecimento das informações disponíveis sobre o assunto. Entre os livros encontrados estão The Design of Lettering, de autoria de Egon Weiss, editado em 1932 pela Pencil Point Press de Nova lorque; Alfabetos e Letreiros, de autoria de A. Ernett, editado em 1944 pela Edições Cultura de São Paulo; e uma edição em espanhol do Manual de Ornamentácion, do alemão F. S. Meyer, da Editora Gustavo Gili de 1947.

O mais interessante deles é "The Design of Lettering", de Egon Weiss. Um livro bastante completo, que trata de maneira ampla do universo das letras. A partir de uma introdução histórica, descreve em capítulos os principais instrumentos para o desenho e escrita; um método para o correto espaçamento dos caracteres; os principais modelos de alfabetos (romano, gótico, itálico, moderno) acompanhado pelas respectivas indicações para sua construção geométrica; monogramas; algarismos; aplicações de letras em diferentes materiais; entalhe em rocha; e uma interessante seção sobre a utilização das letras na arquitetura, acompanhada por exemplos de desenhos de detalhamento para execução de fachadas comerciais.

No acervo do Liceu, foram encontrados alguns exercícios de construção geométrica de letras góticas no estilo Old English. Esses desenhos reproduzem com exatidão os esquemas de construção desse alfabeto contidos no livro de Weiss, o que pode indicar sua provável adoção pelo curso do Liceu (Fig. 2). 


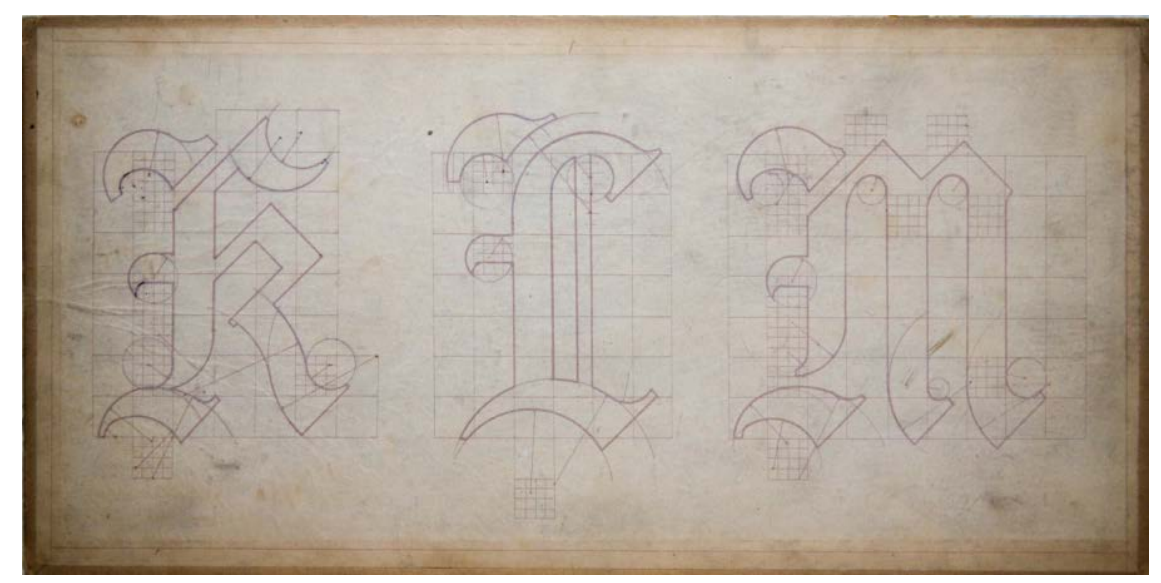

Figura 2 - Exercícios para construção de letras góticas, a partir de princípios geométricos (Acervo do Liceu de Artes e Ofícios).

O livro Alfabetos e Letreiros, de A. Ernett, é um dos volumes da coleção "Série Técnica", editada pela Edições Cultura de São Paulo, em 1944. Praticamente um catálogo de espécimens tipográficos, tem grande quantidade de alfabetos em diferentes estilos, inclusive modernos como a Futura.

O exemplar do Manual de Ornamentácion existente na biblioteca do Liceu, é uma edição em espanhol da Editora Gustavo Gili de 1947. O original em alemão, de Franz Sales Meyer data de 1888. Conforme diz o título, é um manual de ornamentação com um capítulo dedicado às letras e alfabetos. Após uma breve introdução histórica, apresenta figuras ilustrativas de diversos estilos de alfabetos como o românico, o uncial, o gótico, o latino do Renascimento (Romana) e latinas variadas. O manual apresenta também uma reduzida quantidade de referências de monogramas e esquemas para construção geométrica de alguns estilos.

Ainda no acervo, encontrou-se uma série de pranchas rígidas ilustradas, com aproximadamente $60 \mathrm{~cm}$. de largura, que fazem parte da obra "Desenho", de autoria de Carlos Adolpho Marques Leitão, editado em 1909 em Lisboa.

Professor de ensino técnico do Real Colégio Militar e da Escola Industrial Marquês de Pombal, Marques Leitão ficou conhecido pela introdução em Portugal dos trabalhos manuais educativos. Essa obra é composta por cinco volumes, acompanhados por uma série de pranchas para uso expositivo em aula. Cada volume é dedicado a um ano de liceu, e cada prancha ilustra o texto de uma aula com linguagem clara e apurado tratamento gráfico, aliando conhecimentos de desenho geométrico à propostas de aplicações decorativas. (PENIM, 2011).

Entre as diversas pranchas, encontram-se lições de geometria, desenhos de detalhes de ornamentação com tratamento volumétrico por sombreamento e duas pranchas onde estão representados modelos de letras e procedimentos para seu desenho. Na primeira delas (fig. 3), vêem-se letras de desenho geométrico bastante simplificado. São três diferentes modelos, dois de maiúsculas e um de minúsculas, mostradas sobre um malha quadriculada, revelando a estrutura do desenho e facilitando assim seu aprendizado e reprodução. Nenhum desses modelos mostra o alfabeto por inteiro, o que sugere um possível exercício de complementação a ser realizado pelos alunos, a partir dos caracteres apresentados. 
$\mathrm{Na}$ outra prancha encontram-se onze diferentes estilos de alfabetos, desta vez mostrados por completo. São apresentadas letras caligráficas em estilo rondé, com versão em maiúsculas e minúsculas; letras com desenho tipo "bloco"; letras tipo "bastonete" de desenho geométrico simplificado; e alguns exemplos de alfabetos serifados com diferentes tipos de preenchimento, como degradês e efeitos de sombreado. Alguns dos desenhos mais simples apresentam base quadriculada, facilitando o processo de construção e cópia (fig. 4).

Possivelmente, esse material chegou ao Liceu pelas mãos de Ricardo Severo, português que mantinha contato frequente com sua terra natal e com outros integrantes da colônia portuguesa que viviam no Brasil.

O aprendizado do desenho de letras encontrava várias aplicações práticas no Liceu. As letras poderiam ser parte integrante de ornamentos arquitetônicos (fig. 5), de inscrições em placas metálicas, entalhes em móveis, encadernações e também na forma de letreiros comerciais. Por esse motivo, eram ensinadas diversas técnicas para transferência, ampliação e reprodução das letras, do papel para outras superfícies, como o decalque, a quadriculação, o uso de carbonos e processos químicos.

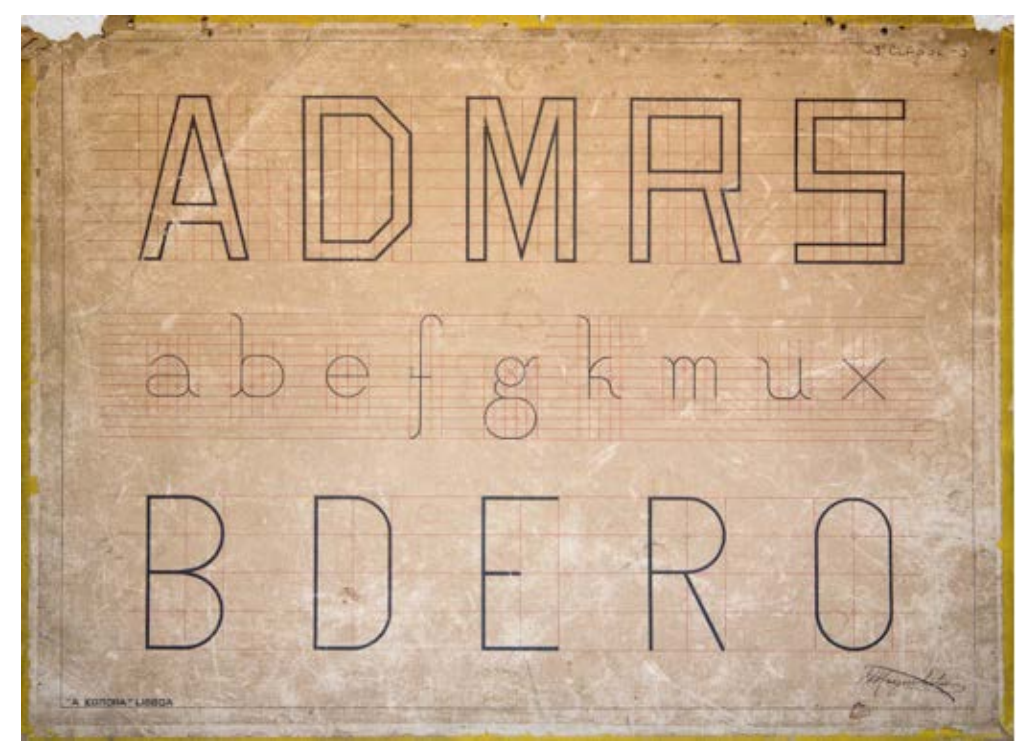

Figura 3 - Prancha do curso "Desenho", do professor português Marques Leitão, mostrando o processo de construção de alguns modelos de letras (Acervo do Liceu de Artes e Ofícios).

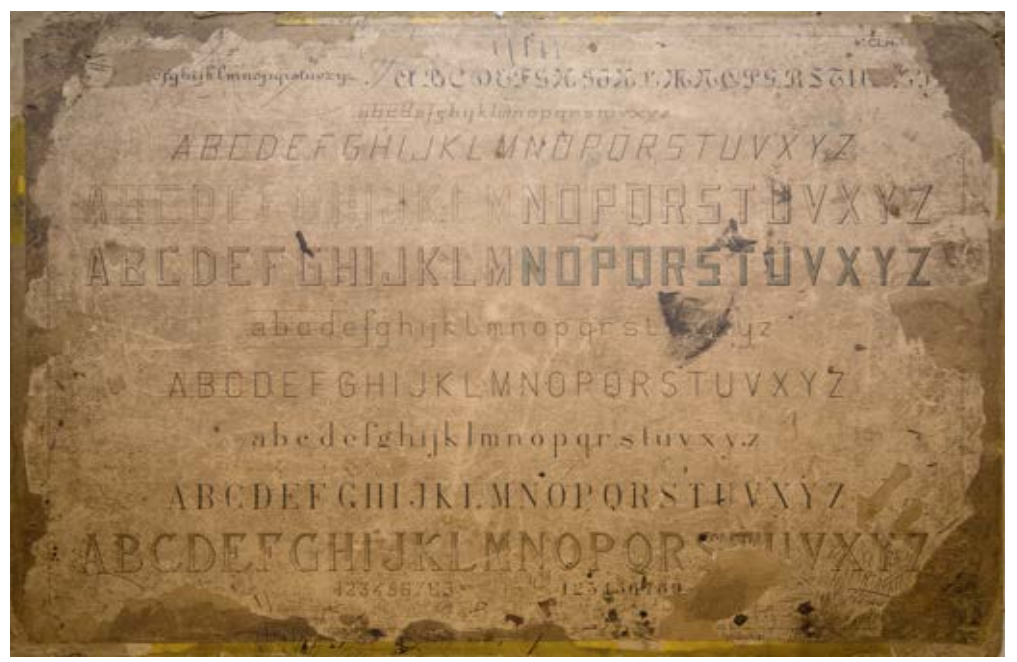

Figura 4 - Mais uma prancha do curso "Desenho", do professor português Marques Leitão, mostrando diversos modelos de alfabetos (Acervo do Liceu de Artes e Ofícios). 
Uma amostra dessas aplicações, pode ser observada nas fotografias que registraram a produção do Liceu existentes em seu acervo. Obras de serralheria artística como guarda-corpos, grades para janelas, portões, bandeiras para portas, etc., muitas delas onde nota-se a presença de iniciais ou monogramas (Fig. 6).

Outro uso dado às letras encontrado nos registros do Liceu, foram os letreiros comerciais, como as grandes letras metálicas conhecidas como letras caixa. Na figura 8 observam-se grandes letras metálicas executadas nessa técnica formando a palavra "ARTES" bem ao fundo da Oficina de Funilaria e Decorações.

Essa oficina, que era dirigida por José Sbarro, executou importantes implantes sanitários para água e esgoto em vários pontos da cidade, além de ter sido responsável pela execução do letreiro instalado sobre a cobertura da Casa Mappin Stores (fig. 9), com letras caixa bastante semelhantes àquelas observadas na figura 8 . Consta que a oficina fez ainda, vários outros trabalhos do gênero em São Paulo, no Rio de Janeiro e em Santos (BERTARELLI, 1924, p. 168).

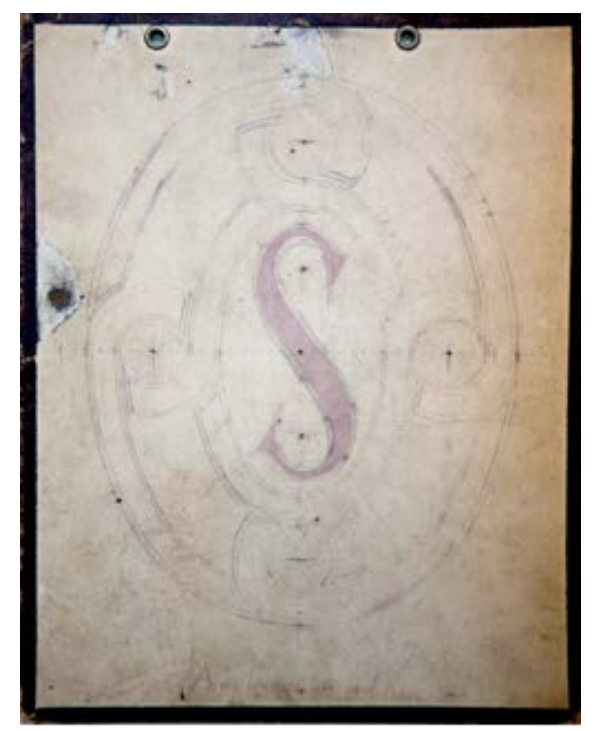

Figura 5 - Desenho de detalhamento de ornamento oval com letra "S" (Acervo do Liceu de Artes e Ofícios).

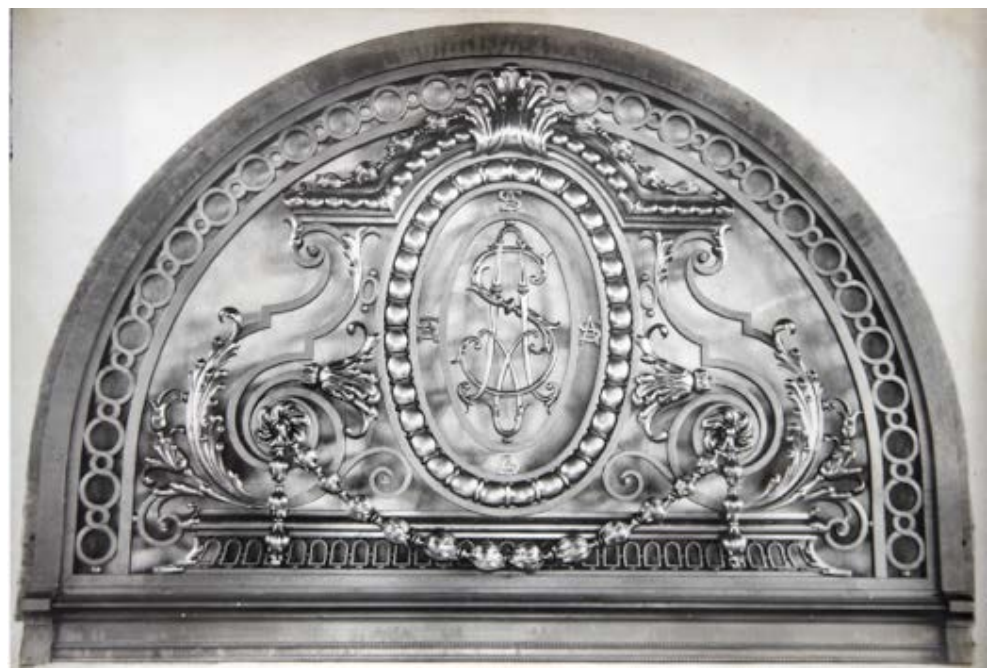

Figura 6 - Bandeira de porta em metal com monograma "SA" (Acervo do Liceu de Artes e Ofícios). 
Outra oficina onde certamente as letras tiveram papel importante, foi a Oficina de Encadernação e Tipografia. Ao contrário da maioria das outras oficinas do Liceu, transferidas em 1907 para instalações na rua da Cantareira devido à falta de espaço, esta permaneceu no edifício da av. Tiradentes. Em 1924 era composta por máquinas para encadernação e douração, onde eram executados trabalhos utilizando couro e marroquim na confecção de carteiras, porta-retratos, cadernos, encadernações artísticas, pergaminho, álbuns de fotografias, além das famosas encadernações com capas feitas a partir de madeiras nacionais (BERTARELLI, 1924, p. 168).

No ensino do desenho de arquitetura, entre os materiais didáticos encontrados, estão pranchas rígidas montadas em cartão de projetos arquitetônicos executados pelo Escritório Técnico Ramos de Azevedo Severo \& Villares ${ }^{3}$, provavelmente utilizadas para ilustração das aulas (fig. 10). Isso demonstra que o intercâmbio entre o Liceu e o Escritório, não ficou restrito apenas aos vários profissionais que atuaram no escritório e como professores do Liceu, entre eles Domiziano Rossi, Felisberto Ranzini, Adolfo Borioni, Américo Giglio e Brasil Ranzini, mas serviram como padrão de ensino de desenho arquitetônico na escola, e provavelmente dos modelos de letras utilizados nos projetos.

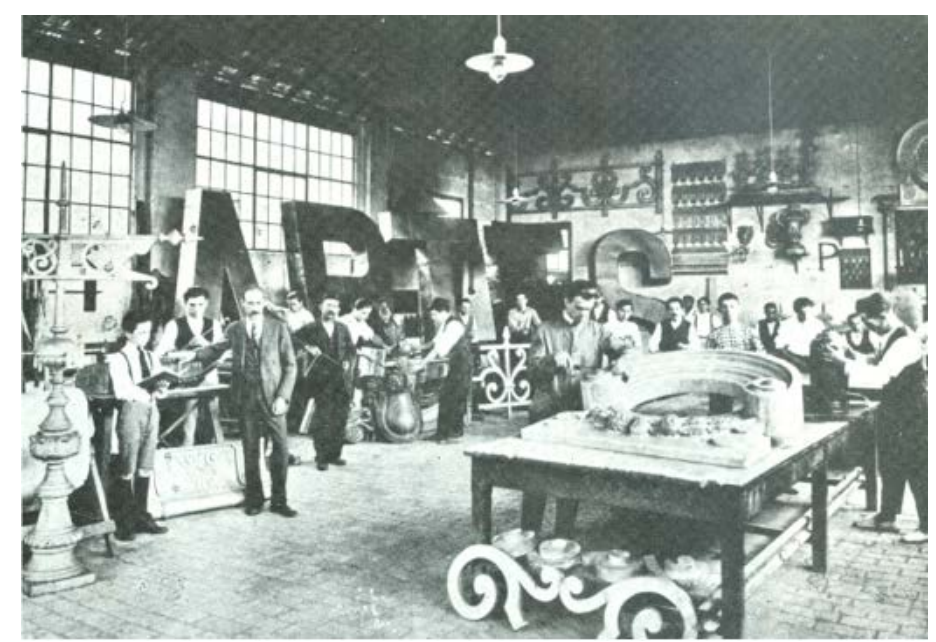

Figura 8 - Oficina de funilaria e decorações (Liceu de Artes e Ofícios, 1984, p. 17).

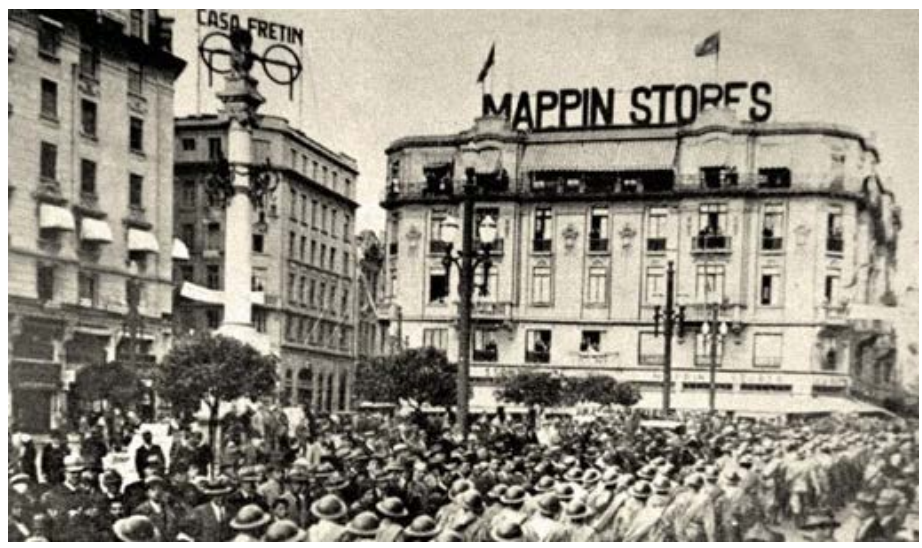

Figura 9 - Casa Mappin Stores, ostentando o grande letreiro executado pelo Liceu de Artes e Ofícios, em 1932 (Blog Tudo por São Paulo 1932, 2012).

\footnotetext{
${ }^{3}$ Nova denominação utilizada pelo E. T. Ramos de Azevedo, quando passou a ser liderado por Ricardo Severo e Arnaldo Dumont Villares.
} 


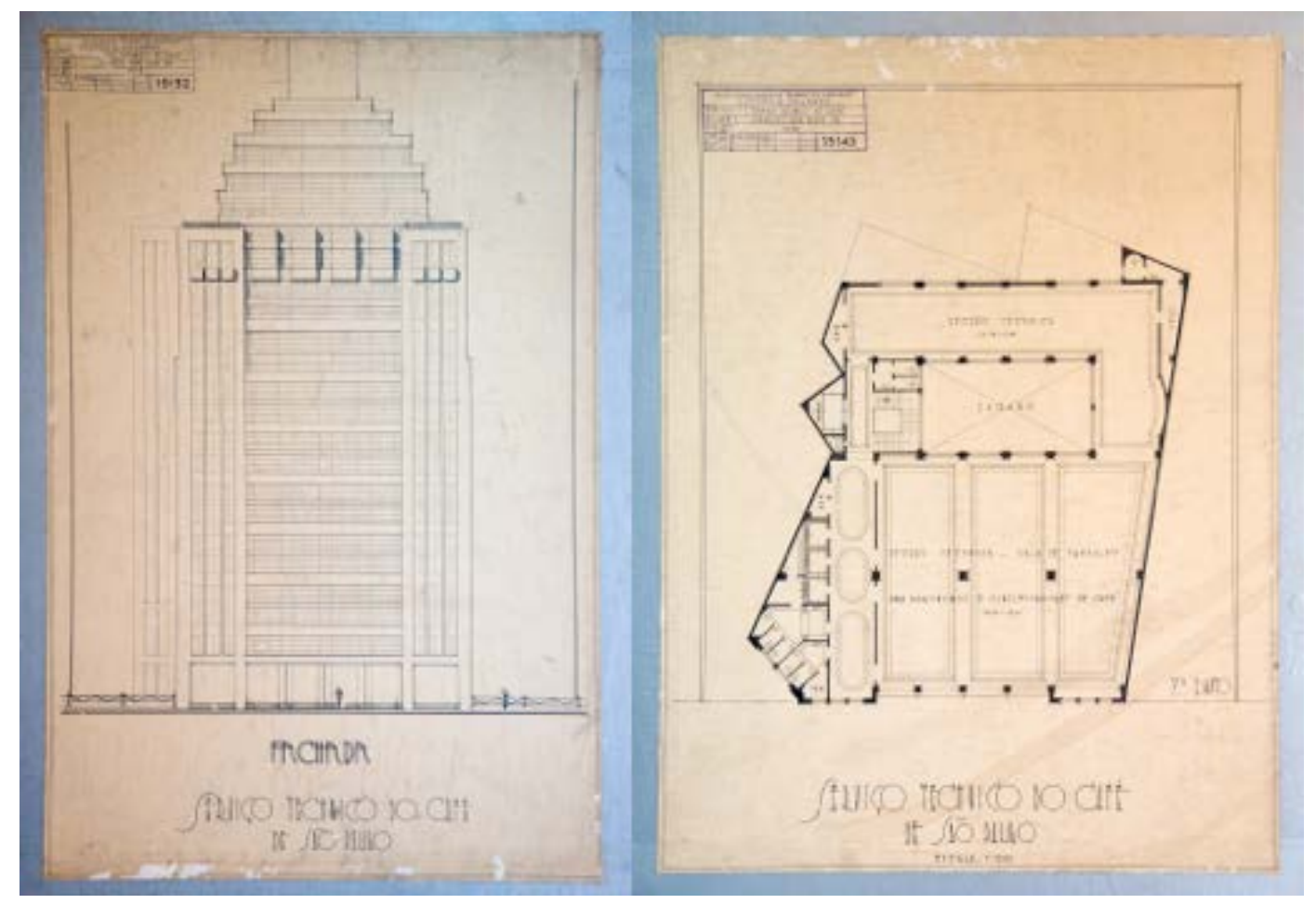

Figura 10 - Projetos do E. T. Ramos de Azevedo, Severo \& Villares de 1934, utilizadas para ilustração de aulas de desenho no Liceu de Artes e Ofícios (Acervo do Liceu de Artes e Ofícios de São Paulo)

\section{CONCLUSÃO}

O Liceu de Artes e Ofícios de São Paulo, desde sua fundação como Sociedade Propagadora da Instrução Popular, teve como principal preocupação o ensino e a qualificação das classes trabalhadoras e, consequentemente, o aprimoramento da escrita, inclusive da caligrafia.

Com o início do ensino profissionalizante, o estudo do desenho de letras e alfabetos passa a ganhar maior importância, principalmente por se tratar de matéria útil para as mais variadas finalidades como gravações, entalhes, fundições, serralheria, modelagem, letreiros comerciais, e também para a produção de trabalhos gráficos desenvolvidos internamente em sua oficina de tipografia e encadernação.

Esse momento, marca também uma mudanca estilística, pois novos modelos de letras, além dos caligráficos, passaram a ser introduzidos no curso, principalmente aquelas obtidas a partir do uso de instrumentos utilizados no desenho técnico e arquitetônico, como réguas, esquadros e tiralinhas. Um bom exemplo disso, são os exercícios para o desenho de letras góticas, feitos a partir do uso desses instrumentos ao invés da pena chata, instrumento que deu origem a esse tipo de caligrafia (fig. 2).

O mesmo ocorre com o ornamento oval da figura 5, clara aplicação do princípio geométrico no desenvolvimento do desenho das letras, demonstrando total sintonia com o mencionado princípio geometral adotado como orientação pedagógica e alinhado com o pensamento positivista dominante à época.

A geometrização do desenho das letras (assim como outros elementos ornamentais) seria utilizada como uma maneira de metodizar um processo, facilitando sua execução e uniformizando sua reprodução. São características bastante claras desse momento de transição entre trabalho artesanal e industrial ou, citando 
BELLUZZO (1988, p. 375), "um momento artesanal da produção industrial e, por outro lado, um momento industrial do trabalho artesanal".

No curso de desenho de arquitetura é real a possibilidade da influência dos métodos e procedimentos utilizados no Escritório Técnico Ramos de Azevedo no processo de ensino do Liceu, dada a quantidade de profissionais que lecionaram e trabalharam nesses dois locais. Segundo BUENO (2015, p. 9), o Liceu teria servido também como celeiro de talentos para o escritório.

A utilização de projetos desse escritório como material didático no Liceu, provavelmente introduziu aos alunos novos padrões e estilos no desenho de letras, como o Art Déco encontrado nas pranchas da figura 10, estilo de sucesso naquele momento, mas inexistente em materiais didáticos mais antigos, como os de Marques Leitão. Portanto, a difusão de padrões e modelos de letras, utilizados pelos arquitetos e desenhistas do escritório Ramos de Azevedo Severo \& Villares entre os alunos do Liceu de Artes e Ofícios, e a partir daí, para outros escritórios da cidade, parece ser uma hipótese passível de ser comprovada.

\section{AGRADECIMENTOS}

À Profa Dra Priscila Lena Farias, pela orientação recebida e ao Liceu de Artes e Ofícios de São Paulo, na figura de sua bibliotecária Alexandra Rebecchi.

\section{REFERÊNCIAS}

BELLUZZO, Ana Maria de Moraes. Artesanato, arte e indústria. 1988. Tese (doutorado) Universidade de São Paulo, Curso de Pós-Graduação em Arquitetura e Urbanismo.

BERTARELLI, Ernesto et. al. Gli Italiani nel Brasile. São Paulo: Pasovino Coloniale, 1924.

BLAKE, Augusto Victorino Alves. Dicionário Bibliográfico Brasileiro. Rio de Janeiro: Typographia Nacional, 1883-1903.

BUENO, Beatriz Piccolotto Siqueira. Escritório Ramos de Azevedo: A Arquitetura e a Cidade. Catálogo de exposição. São Paulo: Correios, 2015.

FONSECA, Joaquim da. Tipografia e Design Gráfico: design e produção gráfica de impressos e livros. Porto Alegre: Bookman, 2008.

FREITAS, Barbosa de. Luiz Aleixo Boulanger (o artista da letra). Disponível em <http://goo.gl/zNA4AO> Acessado em 07 de fevereiro de 2015.

GORDINHO, Margarida C. Liceu de Artes e Ofícios de São Paulo: missão excelência. São Paulo: Marca D’Água, 2000.

LICEU DE ARTES E OFÍCIOS DE SÃO PAULO. 111 anos de Liceu. São Paulo: RMC, 1984.

PENIM, Lígia. Narrativa apanhada em pleno voo. A história do ensino do desenho. In III Colóquio Internacional sobre Desenho: Educação, Cultura e Interatividade. Disponível em <http://goo.gl/rRb7Vq> Acessado em 8 de fevereiro de 2015. UEFS: 2011.

SEVERO, Ricardo. O Liceu de Artes e Ofícios de São Paulo: histórico, estatutos, regulamentos, programas, diplomas. São Paulo: S. N., 1934. 
VIDAL, Diana Gonçalves; GVIRTZ, Silvina. O Ensino da Escrita e a Conformação da modernidade escolar: Brasil e Argentina, 1880-1940. In Revista Brasileira de Educação, no 8, pp. 13-30, ANPEd, 1998. 